\title{
Research on Mechanism of Risk Coupling for Rural Tourism Safety
}

\author{
Jingfeng Luo ${ }^{1,2}$ \\ ${ }^{1}$ College of Tourism, Huaqiao University, Quanzhou 362021, China \\ ${ }^{2}$ Center for Tourism Safety\& Security Research of China Tourism Academy, Quanzhou 362021, China \\ E-mail: luojingfeng2006@126.com
}

Received 26 December 2016

Accepted 27 January 2017

\begin{abstract}
In view of that risk impact processes has not been described and analyzed for rural tourism safety accidents, the paper aims at working out analysis model of risk coupling for rural tourism safety accidents. First, based on the regional environmental risk system theory, the rural tourism safety system is analyzed. Second, under the four dimension of man, machine, environment, and management, the diamond model is established for rural tourism safety risk. Then, based on connotation of coupling, the definition and types of risk coupling was given for rural tourism safety accidents. Finally, based on the periphery theory and trigger working principle, a risk coupling mechanism model of rural tourism safety was established according to the "rural tourism risk trigger". The results may give countermeasures and suggestions to risk management of rural tourism safety.
\end{abstract}

Keywords: Rural tourism, tourism safety, risk coupling, mechanism, trigger, periphery theory

\section{乡村旅游安全风险塊合机理研究}

\author{
罗景峰 ${ }^{1,2}$ \\ 1 华侨大学旅游学院, 福建泉州 362021 \\ 2 中国旅游研究院旅游安全研究基地, 福建泉州 362021
}

\begin{abstract}
摘要：鉴于乡村旅游安全事故风险作用过程迄今未被描述和分析，提出乡村旅游安全事故风险耦合分析模型。 首先, 运用区域环境风险系统理论, 分析乡村旅游安全系统构成及其要素相互作用关系; 其次, 从人、物、环 境及管理的维度出发, 建立乡村旅游安全风险因素钻石模型; 然后, 基于耦合的内涵, 界定乡村旅游安全事故 风险耦合的含义及类型; 最后, 根据界壳与触发器的优势互补性, 建立乡村旅游安全风险耦合机理模型, 并通 过该模型描述了乡村旅游安全耦合风险的形成机理。研究结果可为乡村旅游安全风险管理提供可行对策、合理 建议。
\end{abstract}

关键词: 乡村旅游, 旅游安全, 风险耦合, 机理, 触发器, 界壳理论

罗景峰 (1975-) , 男, 蒙古族, 辽宁阜新人, 讲师, 博士, 国家注册安全工程师, 中国职业安全健康协会会员, 中国系统工程学会会员, 主要研究方向为旅游风险分析与安全评价。

Copyright $($ C 2017, the Authors. Published by Atlantis Press.

This is an open access article under the CC BY-NC license (http://creativecommons.org/licenses/by-nc/4.0/). 
与蓬勃发展的乡村旅游业相比, 乡村旅游安全风 险管理工作尚未受到应有的重视，这与 “安全是旅游 的生命线” 理念极不适应。5.1 凤凰吊桥倾斜、8.7 上 海市青浦区农家乐液化气泄漏爆炸等事故的多风险耦 合特性, 更增加了乡村旅游安全风险防控的难度。从 预防为主的观点出发, 分析乡村旅游安全风险形成机 理，厘清乡村旅游安全风险作用路径，对于有效防控 乡村旅游风险显得至关重要。目前, 有关这一方面的 研究尚未见到相关报道。为此, 在分析乡村旅游安全 风险因素并划分乡村旅游安全耦合风险类型的基础 上, 将界壳理论与触发器工作原理有机结合, 建立乡 村旅游安全风险耦合机理模型, 以期为开展乡村旅游 安全风险管理提供参考和借鉴。

\section{1. 乡村旅游安全系统分析}

借鉴区域环境风险系统理论 ${ }^{[1]}$, 结合乡村旅游安 全实际情况, 乡村旅游安全系统可由风险源、控制机 制和受体三个部分构成, 如图 1 所示。风险源即为可 能产生危害乡村旅游主体(乡村旅游者)、乡村旅游客 体(乡村旅游资源、乡村社区)及乡村旅游媒体(乡村旅

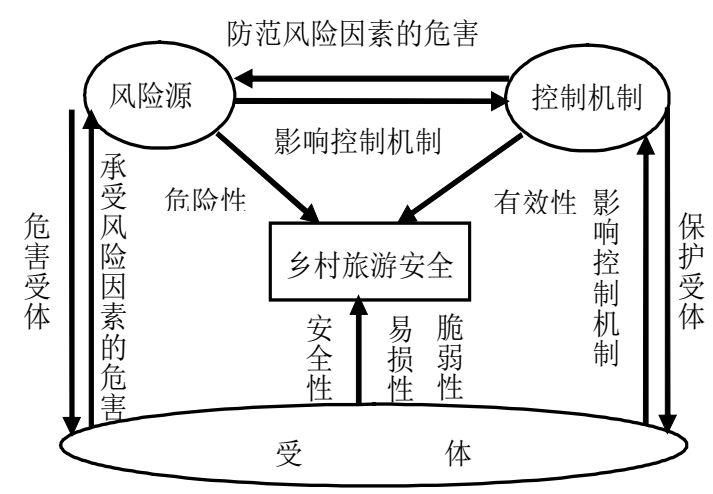

图 1. 乡村旅游安全系统。

游从业者、乡村旅游交通)的源头, 它是乡村旅游风 险事件发生的先决条件; 控制机制包括对风险源的控 制设施设备、管理规章制度等的控制, 它是保障乡村 旅游安全的有效途径和必要手段; 受体则指风险承受 者, 如乡村旅游主体、乡村旅游客体以及乡村旅游媒 体, 它是乡村旅游安全的研究对象。构成乡村旅游安 全系统的三个子系统间存在着相互联系、相互影响关 系，其风险源的 “危险性”、控制机制的 “有效性”、 受体的 “安全性、易损性、脆弱性” 三者的时空交叉 点共同决定了系统的即时安全状态。

由图 1 可知: 风险源的存在是引发乡村旅游安全 事故的前提, 其危险性大小决定对受体的危害程度, 其危险性受控效度直接影响受体的安全状况, 同时,
风险源的动态可变性要求控制机制要根据风险源的 变化情况及时做出调整; 控制机制通过对风险源的有 效控制实现对受体的保护作用的同时, 还需根据受体 的特点、发展及变化态势进行适当调整，以实现对风 险源的动态可靠控制; 受体作为乡村旅游安全的研究 对象, 其安全问题呈现出复杂性、动态性及不确定性 等特点, 一旦受体遭受风险源的攻击, 将发生乡村旅 游安全事故，造成一定的人员伤亡或财产损失。

\section{2. 乡村旅游安全风险耦合分析}

\section{1 乡村旅游安全风险影响因素}

乡村旅游安全 ${ }^{[2]}$ 是指乡村旅游现象中一切安全 现象的总称，既包括乡村旅游主体安全，也包括乡村 旅游客体安全, 还包括乡村旅游媒体安全。根据危险 源理论 ${ }^{[3]}$, 无论是乡村旅游主体、客体或是媒体, 其 安全风险影响因素均可概括为人的因素、物的因素、 环境因素以及管理因素。借鉴波特钻石模型，可将影 响乡村旅游安全风险的因素描述为乡村旅游安全风 险因素钻石模型, 如图 2 所示。由图 2 可知, 人的不

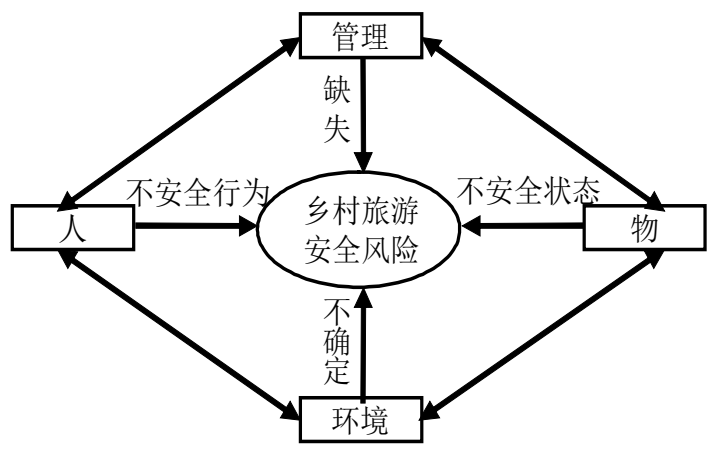

图 2. 乡村旅游安全风险因素钻石模型。

安全行为、物的不安全状态、管理缺失以及环境的不 确定性等是导致乡村旅游安全风险产生的诱发条件, 并且人的因素、物的因素、环境因素及管理因素间存 在着相互联系、相互作用、相互耦合关系，一起乡村 旅游安全事故的发生不仅仅是人、物、环境及管理中 某一单因素作用的结果，更多是各种风险因素非线性 耦合作用的结果。

\section{2 乡村旅游安全风险耦合与耦合风险}

根据耦合的内涵 ${ }^{[4]}$ ，乡村旅游安全风险耦合是指 乡村旅游活动过程中不同风险因素或风险因子之间 的相互依赖、相互影响的关系与程度。于是，乡村旅 


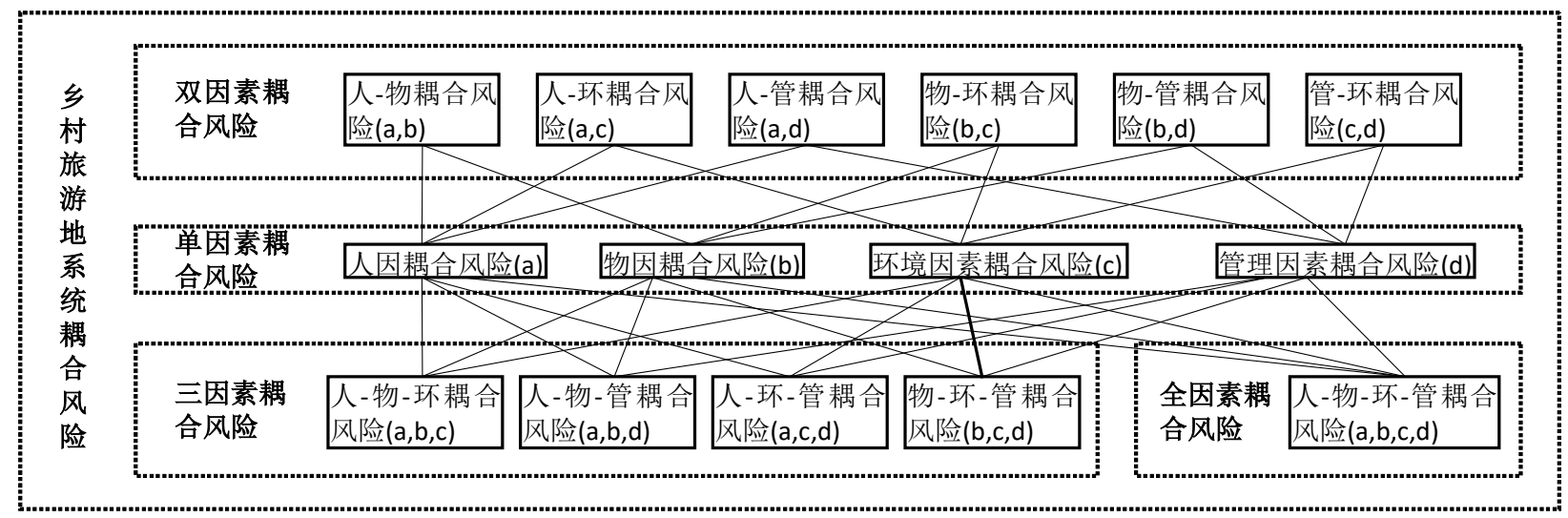

图 3. 乡村旅游安全事故耦合风险类型。

游安全风险耦合方式可以概况为单因素风险耦合、双 因素风险耦合、三因素风险耦合以及全因素风险耦合 等四种。其中，双因素风险耦合、三因素风险耦合与 全因素风险耦合统称多因素风险耦合。风险耦合作用 的结果使得乡村旅游安全系统产生新的风险, 这种新 的风险称为耦合风险, 耦合风险类型如图 3 所示。

单因素耦合风险是指乡村旅游安全系统中人、 物、环境及管理各风险因素自身所包含的风险因子间 相互作用、相互影响所引致的风险，包括人因耦合风 险、物因耦合风险、环境因素耦合风险以及管理因素 耦合风险。例如, 在导游或领队未向游客告知旅游目 的地居民的风俗禁忌的情况下, 游客违反旅游目的地 居民的风俗习惯而引发的主客冲突事故, 就是典型的 人-人风险因素产生的耦合风险。

双因素耦合风险是指乡村旅游安全系统中人、 物、环境及管理风险因素两两相互作用、相互影响所 引致的风险, 包括人-物耦合风险、人-环耦合风险、 人-管耦合风险、物-环耦合风险、物-管耦合风险和管 -环耦合风险。例如，2013 年 5 月 1 日，由于吊桥拉 钩、拉索、受力柱断裂, 加之日常管理维护缺失, 导 致凤凰吊桥发生倾斜事故, 造成 37 名游客落水(其中 2 人轻伤)的后果, 就是一起典型的物-管耦合风险引 发的旅游安全事故。

三因素耦合风险是指乡村旅游安全系统中人、 物、环境及管理风险因素三三相互作用、相互影响所 引致的风险, 包括人-物-环耦合风险、人-物-管耦合 风险、人-环-管耦合风险和物-环-管耦合风险。例如, 由于驾驶员酒驾、游客安全意识不足、逃生门加暗锁、 拼装车横行市场、验车不规范、法律不健全等原因共 同作用，导致台湾旅游大巴事故频发，自 2008 年至 今已造成大陆游客意外死伤共计 298 人, 就是典型的
人-物-管理风险因素相互耦合产生的耦合风险。

全因素耦合风险是指乡村旅游安全系统中人、 物、环境及管理风险因素相互作用、相互影响所引致 的风险, 即人-物-环-管耦合风险。例如, “6.1 东方之 星旅游客船倾覆事件” 造成 442 人遇难, 就是一起典 型的人(船长和当班大副对恶劣天气及其风险认知不 足等)-物(客轮经历三次改建、改造和技术变更，风压 稳性衡准数逐次下降, 虽然符合规范要求, 但不足以 抵抗所遭遇的极端恶劣天气等)-环境( “咆线伴有下击 暴流”带来的强风暴雨等)-管理(恶劣天气预警机制缺 失、旅游客运公司安全管理不到位、应急管理建设薄 弱等)耦合风险引致事故。

\section{3. 乡村旅游安全风险耦合机理}

\section{1 界壳理论及乡村旅游安全界壳}

我国学者曹鸿兴根据系统与环境的作用关系, 开 创性地提出了界壳理论 ${ }^{[5]}$ (Periphery Theory), 指出 “界 壳是处在系统外围能护卫系统且与环境进行交换的中 介体, 它是系统的周界, 是系统的一部分, 又和环境 相毗邻”, 其结构如图 4 所示。其中, 界壁(W)起到卫 护系统本身的功能, 界门(P)通过输入/输出功能可以实 现系统与环境之间进行物质、能量和信息交换。界壳 理论作为系统理论的新成员, 为研究包括气象、生态、 经济、农业、安全等系统周界一般规律提供了崭新的 思路与方法 ${ }^{[5]}$ 。

近年来, 伴随我国安全生产形势的复杂化、风险 防控难度的加大, 一些学者探索性地将界壳理论与安 全风险相关问题结合, 进行了诸多有益探索与创新。 陈勇刚等 ${ }^{[6]}$ 对安全及安全管理界壳进行了初步界定; 黄强等 ${ }^{[7]}$ 提出了系统周界的观控模型, 为水资源多维 


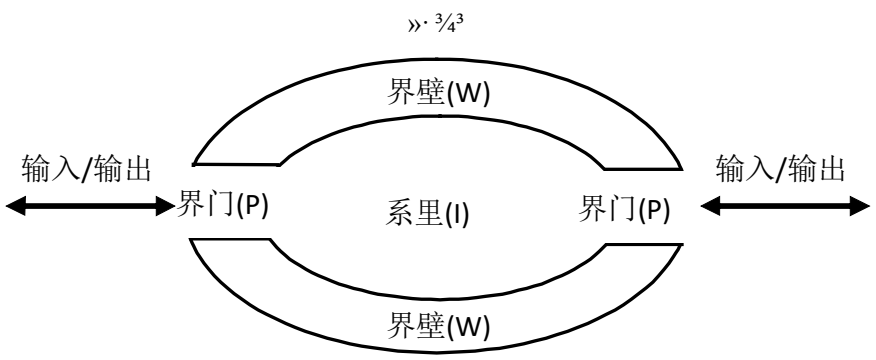

系里: 乡村旅游主体(旅游者);

界壁：旅游者安全指数、旅游从业者安全指数、基础设施、交通 工具、农事体验设施设备、安全标志、安全机构设置和人员配置、 安全生产规章制度、安全监督检查、安全预警机制、安全法律法 规、旅游保险、应急救援、安全投入、安全宣教; 界门: 主客冲突潜在指数以及界壁中的薄弱环节; 环境: 自然灾害、社会治安以及环境卫生等。

图 4. 乡村旅游主体安全事故风险因素管控界壳。

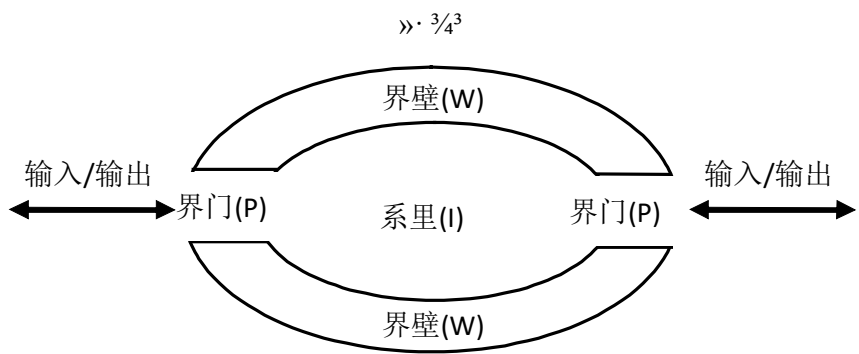

系里: 乡村旅游客体 (乡村旅游资源、乡村社区);

界壁：基础设施、安全设施、资源保护法律法规、资源保护投入、资 源开发利用条件、资源保险、资源容量预警机制、资源保护教育和宣 传、政府监管、社区利益分配公平程度、社区医疗卫生设施、突发事 件应急能力;

界门: 旅游者不文明行为、旅游者碳足迹、生活垃圾和旅游活动污染、 不当的旅游开发、建设性破坏、主客冲突潜在指数以及界壁中的薄弱 环节;

环境：自然生态环境、人文社会环境、社区治安环境、环境卫生等。

图 5. 乡村旅游客体安全事故风险因素管控界壳。

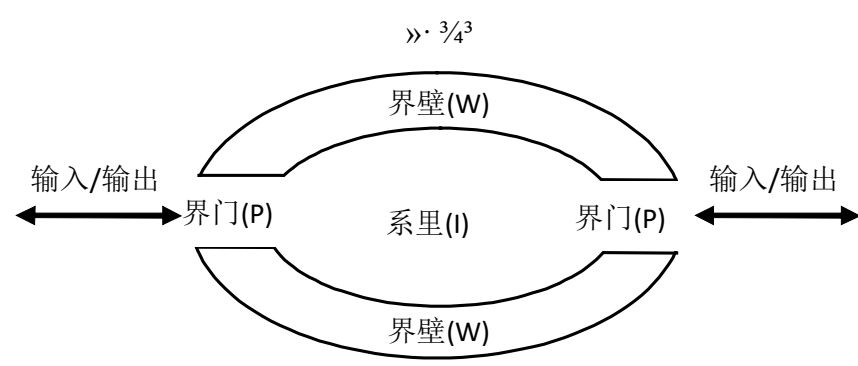

系里: 乡村旅游媒体 (乡村旅游从业者、乡村旅游交通);

界壁: 旅游从业者安全指数、旅游者安全指数、交通工具状况、 交通安全设施标识、交通安全管理状况、安全宣教、事故救援保 障;

界门: 主客冲突潜在指数、驾驶员情况以及界壁中薄弱环节; 环境：旅游从业者所处环境、天气状况、道路状况等。

图 6. 乡村旅游媒体安全事故风险因素管控界壳。 
临界调控风险分析提供了新途径; 郑怀昌等 ${ }^{[8]}$ 利 用界壳理论分析了矿山系统安全风险产生机理, 并提 出防控策略; 刘朝峰等 ${ }^{[9]}$ 提出了地震灾害综合防御界 壳的协同演化测度模型。综上, 界壳理论在提升系统 风险防控能力、保障系统安全上具有很好的适用性。

于是, 在对乡村旅游安全系统及其安全风险影响因素 分析的基础上 ${ }^{[2]}$, 根据界壳理论, 构建乡村旅游主体 安全事故风险因素管控界壳、乡村旅游客体安全事故 风险因素管控界壳以及乡村旅游媒体安全事故风险因 素管控界壳, 如图4、5、6所示。

\section{2 乡村旅游安全风险耦合机理}

分析乡村旅游安全风险耦合机理, 有助于厘清乡
村旅游安全各风险因素耦合作用路径, 为降低风险、 提高防控能力提供科学参考, 同时也是建立有效的乡 村旅游安全保障体系的必要前提。基于触发器工作原 理的风险形成机理模型 ${ }^{[4,10]}$ 可为乡村旅游安全风险耦 合机理研究提供思路和借鉴, 但该模型亦存在两点不 足:(1)理论基础薄弱; (2)模型中阀门和滤波器仅具有抵 抗(被动的防御)、自修复、自组织等有限功能, 缺乏 主动防御功能、缺乏系统与外界环境进行物质、能量 和信息交换机制等。而界壳 ${ }^{[5-9]}$ 具有坚实的理论基础、 完善的系统卫护、交换及抵抗等功能, 但却不具备耦 合功能。为此, 将界壳功能与触发器的耦合振荡器功 能进行有机结合, 建立一种优势互补的乡村旅游安全 风险耦合机理模型, 如图 7 所示。

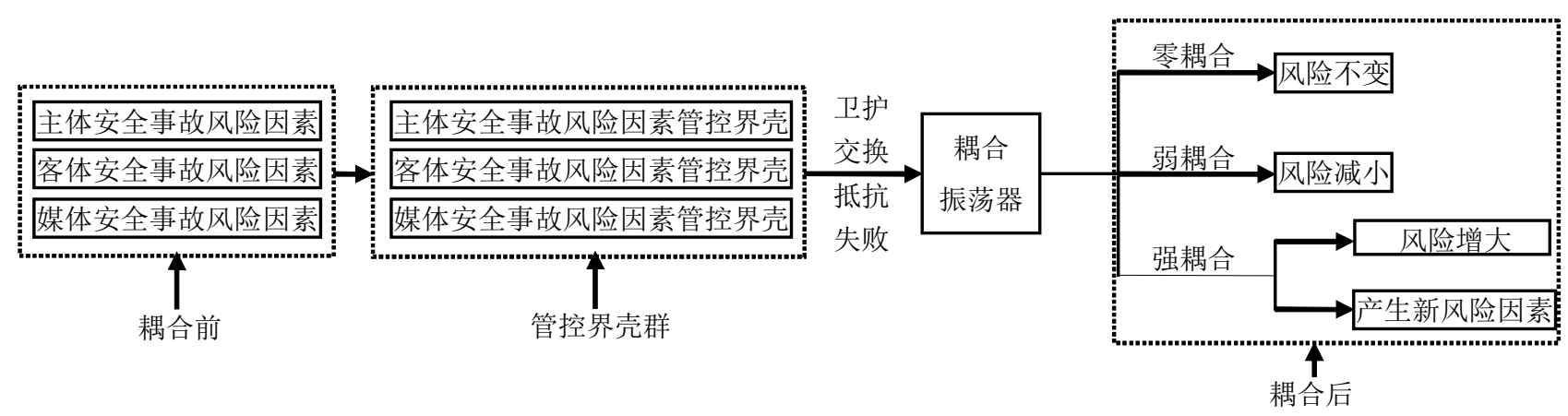

图 7. 乡村旅游安全风险耦合机理模型。

由图 7 可知: 当乡村旅游主体、客体及媒体安全 事故风险因素管控界壳的卫护、交换及抵抗均成功 时, 各风险因素不会通过管控界壳而进入耦合振荡器 进行风险耦合, 乡村旅游安全风险处于可控状态, 不 会引发乡村旅游安全事故; 当乡村旅游主体、客体及 媒体安全事故风险因素管控界壳中任一管控界壳的 卫护、交换及抵抗失败时, 其对应风险因素会通过管 控界壳群而进入耦合振荡器进行风险耦合, 产生耦合 风险, 此时乡村旅游安全风险处于不可控状态, 将会 引发乡村旅游安全事故。根据耦合振荡器对风险的耦 合程度, 耦合风险包括零耦合、弱耦合和强耦合三种 类型 ${ }^{[4]}$ 。零耦合是指风险通过耦合振荡器之后, 风险 保持不变; 弱耦合是指风险通过耦合振荡器之后, 风 险减小或降低; 强耦合是指风险通过耦合振荡器之 后, 风险增大或产生了新的不可预知的风险。按照系 统安全的观点, 既然风险是绝对的, 则防控乡村旅游 安全风险就应该做到 “避免强耦合、追求零耦合或弱 耦合, 将风险保持到可控程度”。

\section{4. 结论}

乡村旅游安全是一个复杂系统工程问题, 无论是 其受体构成要素的乡村旅游主体、客体及媒体, 或是 导致乡村旅游安全事故发生人、物、环境及管理等风 险引致因素, 均呈现出复杂性、不确定性和可变性等 特点, 这更增加了乡村旅游安全风险防控的难度。分 析乡村旅游安全风险耦合机理, 可以从风险产生的源 头和作用路径上为风险管控工作提供参考依据。本文 在分析乡村旅游安全系统及其风险因素的基础上, 对 乡村旅游安全耦合风险类型进行了具体划分, 并依据 触发器原理、界壳理论提出了乡村旅游安全风险耦合 机理模型, 得到如下结论:

(1)乡村旅游安全系统是风险源、控制机制、受体 及三者相互作用关系的集合, 其风险源的 “危险性”、 控制机制的 “有效性”、受体的 “安全性、易损性、脆 弱性” 三者的时空交叉点共同决定了乡村旅游安全系 统的即时安全状态。 
(2)一起乡村旅游安全事故的发生不仅仅是人、 物、环境及管理中某一单因素作用的结果，更多是各 种风险因素非线性耦合作用的结果。

(3)乡村旅游安全风险耦合方式可以概括为单因 素风险耦合、双因素风险耦合、三因素风险耦合以及 全因素风险耦合等四种类型, 乡村旅游安全风险的耦 合产生乡村旅游安全耦合风险。

(4)所建立乡村旅游安全风险耦合模型, 以风险 管控界壳取代触发器的阀门与过滤器的功能, 并保留 触发器耦合振荡器的耦合功能, 做到优势互补, 无论 是在理论支撑或是在对风险耦合作用路径描述上, 更 为科学合理。同时, 该风险耦合机理模型也为如何管 控乡村旅游安全风险、降低乡村旅游安全事故率提供 对策参考, 即可通过构造乡村旅游主体、客体及媒体 安全事故风险因素管控界壳以防止风险溢出并进一 步耦合产生耦合风险, 另外, 在此基础上还可构造乡 村旅游主体、客体及媒体安全保障界壳以卫护乡村旅 游主体、客体及媒体的安全。

\section{致谢}

本文得到福建省社科规划一般项目 (FJ2015B217); 福建省中青年教师教育科研项目 (JAS150095); 中央高校基本科研业务费资助项目・华 侨大学哲学社会科学青年学者成长工程项目 (14SKGC-QG16)的资助, 在此表示衷心感谢。

\section{参考文献}

1. 毕军,杨洁,李其亮. 区域环境风险分析和管理.北京:中国 环境科学出版社,2006.

2. 罗景峰.乡村旅游安全影响因素辨识研究.安徽农业大学 学报(社会科学版),2016,26(4):30-34.

3. 隋鹏程,陈宝智,隋旭.安全原理.北京:化学工业出版 社,2005.

4. 张津嘉,许开立,王贝贝,等.瓦斯爆炸事故风险耦合演化机 理研究.中国安全科学学报,2016,26(3):81-85.

5. 曹鸿兴,封国林,蔡秀华,等.界壳论精要及其应用.北京:科 学出版社,2011.

6. 陈勇刚,田水承,李红霞.界壳论与矿山安全管理界壳基础 研究.中国矿业,2003,12(11):18-20.

7. 黄强,李勋贵,LEON Feng,等.系统周界的观控模型及其应 用.系统工程理论与实践,2005,25(3):101-106.

8. 郑怀昌,李明.界壳理论在采空区失稳判定与危害控制研 究中的应用探讨.黄金,2005,26(12):19-22.

9. 刘朝峰,苏经宇,王威,等.地震灾害综合防御界壳的协同演 化测度模型.系统工程理论与实践,2014,34(8):2186-2192.

10. 冯艳飞,陈媛.企业战略风险的形成机理研究.武汉理工大 学学报(信息与管理工程版),2008,30(5):816-819. 